\title{
RESPONSABILIDADE SOCIOAMBIENTAL - ESTAÇÕES PARA COLETA SELETIVA
}

Patricia de Faccio Rissi ${ }^{1}$, Guilherme Mendez Freire dos Santos ${ }^{2}$

${ }^{1}$ Universidade Anhembi Morumbi, MBA em Gestão de Projetos, São Paulo, SP. ${ }^{2}$ Faculdade de Arquitetura e Urbanismo de Santos - FAUS, Curso de Arquitetura e Urbanismo, Santos, SP.E-mail: arq.patricia.rissi@gmail.com.

\section{RESUMO}

Este artigo visa à necessidade de atitudes empreendedoras na cidade de Presidente Epitácio, com um apelo principal na responsabilidade socioambiental dos munícipes. Observou-se um grande bloqueio na colaboração da coleta seletiva local, todos os motivos desse bloqueio foram seccionados e o resultado final que melhor atendeu as necessidades do município serão estações de coletas distribuídas estrategicamente nas principais áreas residenciais e comerciais da cidade. Uma atitude empreendedora, por sua vez, quando bem planejada, pode gerar uma economia anual enorme nos gastos de uma prefeitura, que consequentemente, passa a priorizar investimentos que anteriormente faltavam recursos, melhorias que interferem principalmente na vida dos próprios moradores. Este artigo comprova que apenas $38 \%$ do gasto anual com o setor de coleta seletiva de Presidente Epitácio são necessários para melhorar a situação dos coletores e deliberar as reclamações dos habitantes da cidade.

Palavras-Chave: coleta seletiva; reciclagem; responsabilidade socioambiental; Presidente Epitácio; empreendedorismo.

\section{SOCIO-ENVIRONMENTAL RESPONSIBILITY - STATIONS FOR SELECT COLLECTION}

\begin{abstract}
This article aims the need for entrepreneurial attitudes in Presidente Epitacio city, with the appeal in citizen environmental responsibilities. There is a big lock on the collaboration of the local selective collection, all the reasons for this lock were separated and the best result was strategically distributed collection stations in residential and commercial areas in the city. An entrepreneurial attitude, in turn, when well planned, can save a lot of money in one particularly city hall, which consequently passes to prioritize investments that previously lacked resources, improvements that primarily affect the citizens. This article shows that only $38 \%$ of annual expenditure on the selective collection sector of Presidente Epitacio are needed to improve the situation of the collectors and resolve the complaints from the residents.
\end{abstract}

Keywords: selective collection; recycling; socio-environmental responsabilities; Presidente Epitácio; entrepreneurship. 


\section{INTRODUÇÃO}

Em Presidente Epitácio, a porcentagem de habitantes que colaboram com a coleta seletiva diminuiu muito nos últimos doze meses, como confirma a Secretaria do Meio Ambiente de Presidente Epitácio (2016). A cooperativa foi contratada em janeiro de 2015 (site Portal Joia Ribeirinha, 2015) e o motivo pelo qual essa porcentagem é tão baixa aplica-se perfeitamente no conceito de Self-Deception segundo The Arbinger Institute (2010).

Pode-se dizer que $99,9 \%$ dos munícipes sabem que o correto é separar a matéria orgânica do material reciclável, este assunto é abordado com frequência na televisão, em jornais, nas escolas dos filhos, em mutirões pela cidade, de fato, é um assunto totalmente desconhecido por poucos. Mas então por qual motivo as pessoas não participam da coleta seletiva? Os motivos são vários segundo a Secretaria do Meio Ambiente da cidade, e as pessoas encontram cada vez mais motivos que justifiquem esse ato, com fundamentos que as convencem fortemente de estarem corretas, e assim, não participarem da coleta seletiva da cidade, características claras (que serão aprofundadas ao longo do presente trabalho) de um comportamento Self-Deception, segundo Warren (2014). O ser humano se autoengana constantemente nesse conceito, alguns com mais frequência do que outros conforme diz Triandis (2013), isso não é uma exclusividade apenas dos habitantes de Presidente Epitácio, porém, há diferenças entre ações que interferem apenas internamente uma única residência e ações que interferem externamente, ações que interferem no bairro, na cidade, no país e no mundo.

Para Fingarette (2000), Self-Deception é quando um sujeito chega em casa cansado após um dia de trabalho e se depara com uma pia cheia de louça para lavar, porém, o pensamento que vem em sua cabeça é de como aquela situação é injusta: chegar em casa depois de um longo dia de serviço e ainda ter que lavar louça. Isso é Self-Deception, a pessoa engana a si mesmo, o fato de ela chegar cansada do trabalho justifica fortemente o porque de não lavar a louça naquele momento. Porém, esse é um exemplo muito simples, um exemplo de algo que interfere diretamente apenas em uma única residência na cidade. E quando o Self-Deception interfere na vida de mais pessoas? Outro exemplo clássico: estacionar na vaga de um portador de necessidades especiais. Sabe-se que não é correto, porém, fazem mesmo assim. Automaticamente ao ver que há apenas essa vaga disponível no estabelecimento, a pessoa pensa em mil desculpas que justifiquem o fato de ela estacionar naquela vaga, "é só dessa vez", "estou com pressa", "vai ser rapidinho", são desculpas que a maioria já ouviu. Porém, ao olhar para a vaga de portadores de necessidades especiais, a pessoa automaticamente tem um leve "breque" em sua mente, é aquele milésimo de segundo em que o cérebro avisa de que ela sabe que vai fazer algo errado, porém, logo em seguida aparecem as desculpas de sempre. É exatamente esse "breque" que é o Self-Deception, a pessoa se depara com a ação errada, pensa no que na verdade deveria fazer e não faz. Segundo Goffi (2016), pode-se traduzir este conceito para "Caixa da Justificativa", é como se naquele momento de decisão caísse uma caixa invisível sobre a pessoa e a partir de então ela está dentro da caixa, e dentro desta caixa há mil desculpas para utilizar da maneira que preferir. E é exatamente isto que acontece com os habitantes da Presidente Epitácio quando o assunto é "coleta seletiva".

Não separar a matéria orgânica do material reciclável é algo totalmente interno, mas que reflete vigorosamente o mundo externo. E as desculpas relatadas pelos coletores do município apenas comprovam como este é um caso claro de Self-Deception.

Neste contexto, o presente trabalho objetiva eliminar todas as "dificuldades" dos munícipes em separar o material reciclável através de estações de coletas posicionadas estrategicamente em áreas residenciais e comerciais de Presidente Epitácio, enfatizando a falta de responsabilidade socioambiental dos moradores e os problemas gerados devido a atual situação. 


\section{METODOLOGIA}

A metodologia utilizada se constitui em pesquisa bibliográfica composta de material já produzido e elaborado (livros, artigo científico e palestra). Por se tratar de um tema descritivo, foi imprescindível a obtenção de informações referentes à coleta seletiva da cidade na Secretaria do Meio Ambiente e na Cooperativa de Catadores de Materiais Recicláveis de Presidente Epitácio (Cooperarpe), para a compreensão e elaboração do presente trabalho.

\section{SELF-DECEPTION NA COLETA SELETIVA}

Segundo a pesquisa realizada, a desculpa mais comum é a falta do "saco verde", um saco plástico de 200 litros que a prefeitura distribuía nas residências semanalmente para incentivar os moradores a separarem o material reciclável. Devido aos recentes acontecimentos do país, vários gastos foram reduzidos e alguns até mesmo cortados provisoriamente (situação atual do saco de 200 litros) na prefeitura de Presidente Epitácio, e isso irritou profundamente a maioria dos munícipes. Frases como "isto é um absurdo, querem que separemos o lixo, mas não fornecem o saco" são extremamente comuns entre os vizinhos.

Outra justificativa forte dos habitantes é não saber o dia correto de colocar o material reciclável na calçada (o material é recolhido apenas uma vez por semana em cada bairro), eles afirmam se confundirem muito e como alguns utilizam o próprio saco preto de lixo orgânico, ao colocá-lo na calçada em um dia errado, a coleta de orgânicos recolhe e todo o "trabalho" que houve para fazer a separa dos materiais acaba sendo em vão, e por outro lado, afirmam casos de a própria coleta seletiva não recolher o saco preto (pois acreditavam ser lixo orgânico), assim, desistiram de participar e afirmam apenas voltar a colaborar quando a prefeitura disponibilizar o saco verde.

A forma de abordagem da coleta seletiva também é muito criticada pelos moradores, os coletores passam pelas ruas aos gritos da palavra "reciclagem" e pegam de portão em portão o material separado pelos munícipes (visto que apenas deixar na calçada não foi uma boa opção). Segundo os habitantes, essa abordagem não é eficiente, pois o chamado dura apenas alguns segundos (o fato desse chamado durar tão pouco é apenas um reflexo de como só algumas residências colaboram com a coleta, se houvessem mais casas participando, a abordagem seria consequentemente mais lenta), quando as pessoas aparecem finalmente na calçada com o material, os coletores já se foram e assim, uma nova desculpa é gerada: o acúmulo.

Se um morador perde a passagem da coleta seletiva, isto significa que ele terá uma semana extra de material reciclável acumulado em sua casa. Muito habitantes reclamam que não possuem espaços adequados para armazenar o material reciclável (garrafas PETs, caixas de leite, latas, entre outras embalagens acumulam facilmente um grande volume), sempre colocam em um canto no quintal, que trás uma péssima aparência para o ambiente ou se torna um alvo para animais domésticos bagunçarem (principalmente cachorros). De fato, esse é um problema que muitos moradores enfrentam, afinal, dificilmente os profissionais projetam residências preparadas para acumular o material reciclável da mesma maneira como preparam para acumular o material orgânico, nunca esquecem uma lixeira na hora do projeto, pois isso já é um hábito no Brasil há muitos anos. Por que projetar um espaço para o material reciclável não é um hábito ainda?

\section{ESTAÇÕES DE COLETA SELETIVA}

Todas as desculpas que os munícipes utilizam para justificar o fato de não participarem da coleta seletiva da cidade, conforme citado no tópico anterior, serão eliminadas com a instalação de estações em pontos estratégicos nas áreas residenciais e comerciais de Presidente Epitácio.

Com apenas três tambores reaproveitados e instalados no meio-fio das ruas (Figura 1), as pessoas colocarão seus materiais recicláveis em sacos pretos, sacos verdes, sacos transparentes, sacolas de supermercados, enfim, a cor do saco não causará mais transtornos e não será um 
motivo para não participar da coleta. Não importa qual o dia dos coletores passarem no bairro, quem determina o horário de colocar o material reciclável nos tambores são os próprios moradores. Os lixeiros não pegarão mais os recicláveis por engano, pois estão informados de que os tambores não contem material orgânico. Não há mais necessidade dos coletores usarem o "chamado da reciclagem" nas ruas, pois os habitantes já terão transferido tudo de suas casas para os tambores, e assim, não correm mais o risco de acumularem uma semana extra de material reciclável, cada um deposita o que acumulou ao seu tempo. O motivo pelo qual as estações serão preferencialmente implantadas no meio-fio é para facilitar a coleta da cooperativa e evitar ao máximo alterar a calçada dos moradores.

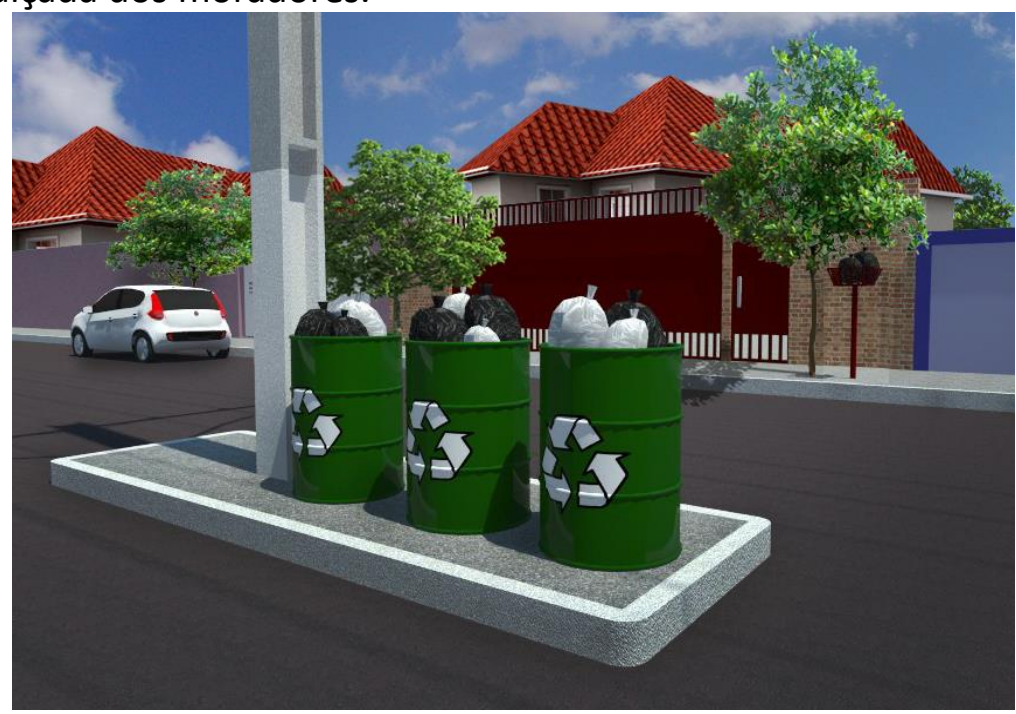

Figura 01. Protótipo apresentado à Secretaria do Meio Ambiente de Presidente Epitácio.

Fonte: Dos autores, 2016.

\section{RESULTADOS}

A estação protótipo foi instalada em agosto de 2016 e seu custo foi de $R \$ 150,00$. O protótipo agradou bastante os moradores do quarteirão e o retorno superou as expectativas logo na primeira semana, pessoas que não colaboravam mais com a coleta seletiva voltaram a separar o material reciclável do material orgânico e pessoas que nunca colaboraram anteriormente passaram a separar devido ao incentivo dos vizinhos. O objetivo final deste trabalho era justamente aumentar o volume coletado, o protótipo prova este resultado e as estações implantadas no município inteiro ajudarão esse volume a crescer ainda mais.

Inicialmente, as estações serão implantadas na Avenida Presidente Vargas e em suas ruas paralelas, Maceió e Fortaleza, com previsão para o segundo semestre de 2017. A estratégia é implantar inicialmente nestas três ruas para que os próprios moradores divulguem esta nova iniciativa do município, pelo fato da maioria da população circular diariamente ou no mínimo semanalmente por esse trajeto, sendo inevitável notar as novas estações. Para a distribuição completa nessas três ruas iniciais, será necessário 30 estações (90 tambores, 3 tambores por estação), seu custo será de $R \$ 13.500,00$, visto que o protótipo custou $R \$ 150,00$.

Para as estações funcionarem na cidade inteira, é necessário dividir esta expansão em duas etapas: $65 \%$ da cidade está preparada para receber as estações de imediato, assim como a parte inicial do projeto na avenida e suas ruas paralelas, devido a presença do meio-fio (Figura 2); e em $35 \%$ da cidade não há meio-fio, será necessário algumas adaptações para atingir 100\% (Figura 3). 


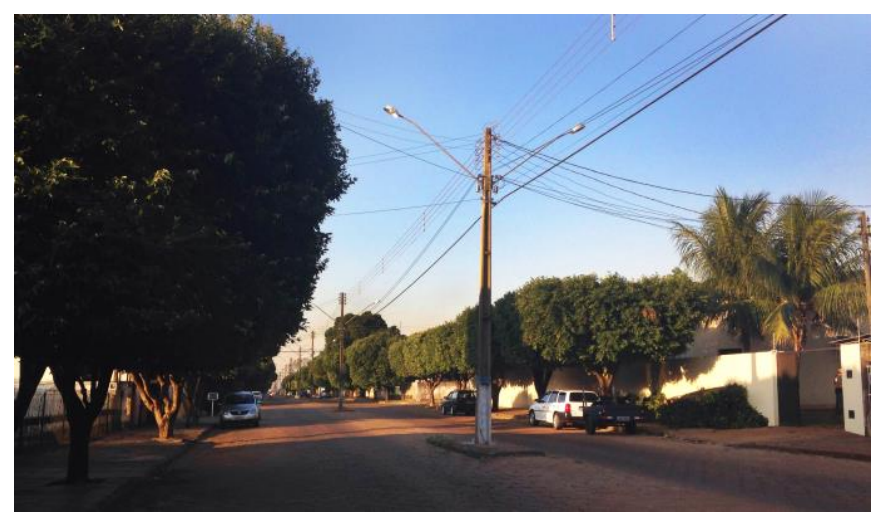

Figura 02. Exemplo de rua que apresenta meio-fio em Presidente Epitácio. Fonte: Dos autores, 2016.

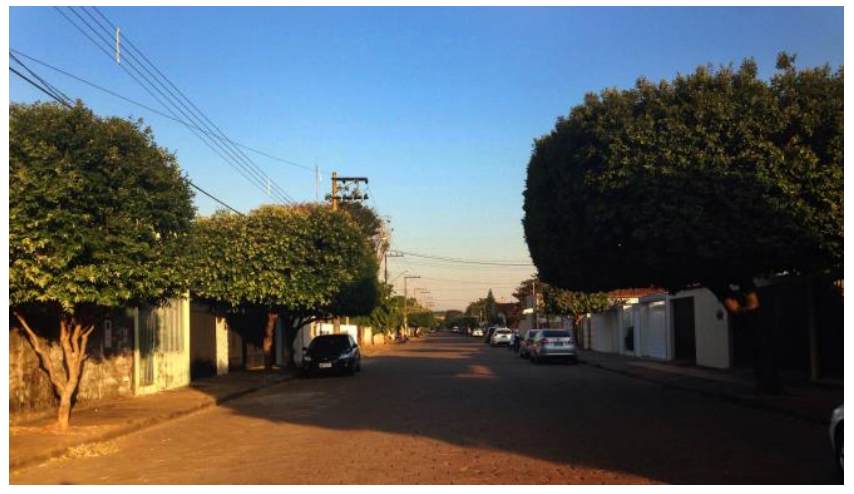

Figura 03. Exemplo de rua que não apresenta meio-fio em Presidente Epitácio.

Fonte: Dos autores, 2016.

De $35 \%$ da cidade que não há meio-fio, parte da solução é implantar as estações em: escolas, praças, comércios, entre outros. E $19 \%$ desta porcentagem é possível resolver dessa maneira, os outros $18 \%$ são quadras apenas residenciais e será necessário a compreensão dos munícipes para que as estações sejam instaladas na calçada de residências que menos afetem a rotina do morador e não atrapalhe o passeio público (Figura 4).

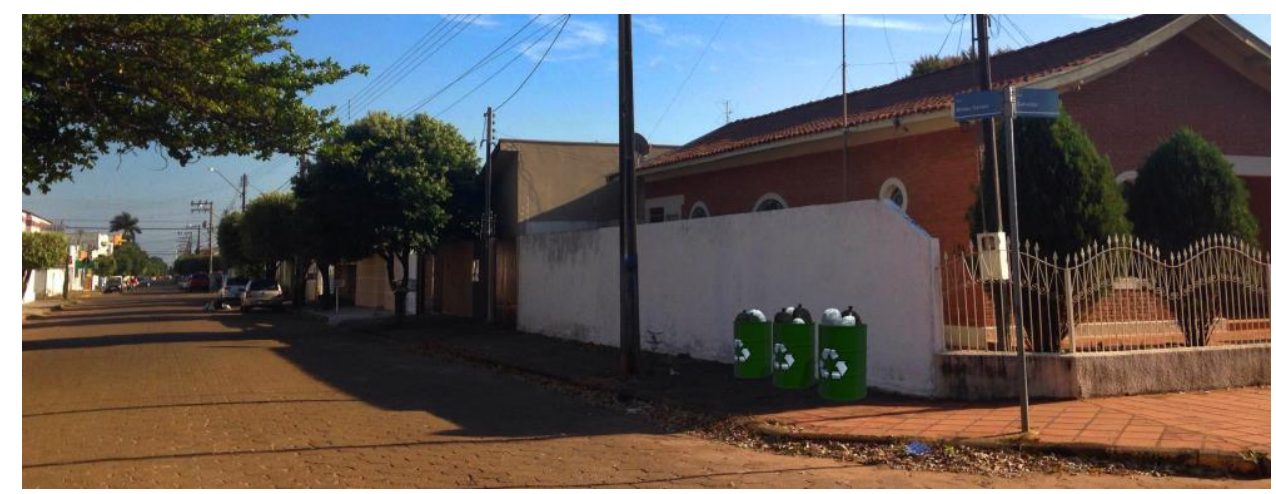

Figura 04. Exemplo de residência ideal para implantar as estações.

Fonte: Dos autores, 2016.

$\mathrm{Na}$ área de $65 \%$ em que as estações podem ser implantadas de imediato, será necessário 163 estações (489 tambores), custará $\mathrm{R} \$$ 73.350,00 e está prevista para o primeiro semestre de 2018. Na área de 35\% que precisará de adaptações, será necessário 106 estações (318 tambores), custará R\$ 47.700,00 e está prevista para o segundo semestre de 2018. 


\section{DISCUSSÃO}

Há um novo aterro sanitário em construção em Presidente Epitácio, uma obra no valor de $\mathrm{R} \$$ 4.205.946,83 (site Portal Joia Ribeirinha, 2016). Cada trincheira do aterro (sendo quatro no total) possui uma previsão de cinco anos para chegar ao seu limite, mas, se a coleta seletiva estiver com um desempenho melhor, essas trincheiras podem aumentar essa previsão para sete anos e assim prolongar a vida do aterro de vinte para vinte e oito anos.

Além de melhorar a situação atual da coleta seletiva e resolver as "dificuldades" dos munícipes em separar o material reciclável, há outro grande benefício para a prefeitura de Presidente Epitácio. Com as estações implantadas na cidade inteira (Figura 5), o custo será de R\$ 134.550,00 e utilizará 897 tambores reaproveitados, porém, o custo anual que a prefeitura tem para a distribuição do saco de 200 litros para a coleta do material reciclável é de aproximadamente $\mathrm{R} \$ 350.000,00$ segundo a Secretaria do Meio Ambiente de Presidente Epitácio (2016), verba que atualmente está cortada temporariamente devido à situação atual do país. Ou seja, uma clara economia anual para o município, pois não existirá mais a necessidade de distribuição do saco verde.

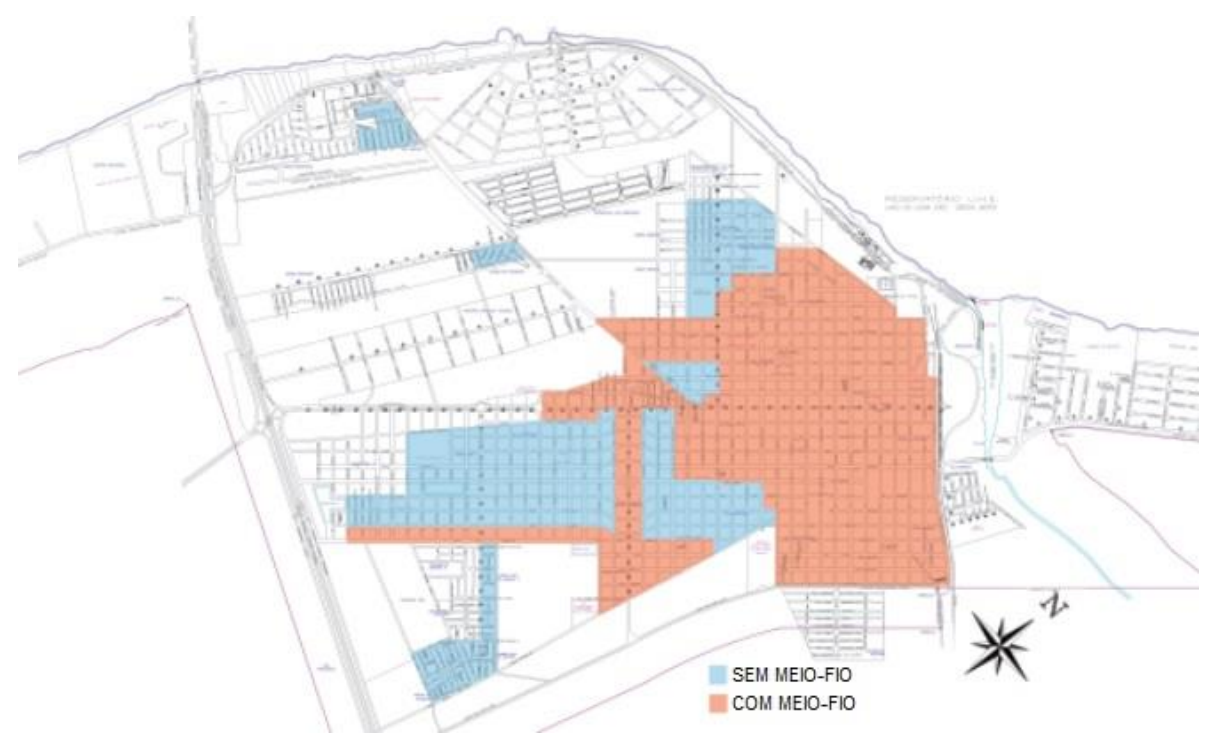

Figura 05. Município de Presidente Epitácio com 100\% das estações implantadas.

Fonte: Dos autores, 2016.

Em caso de vandalismo, cabe à prefeitura fazer a manutenção da estação danificada. É necessário persistir para que a presença dos tambores se torne tão comum quanto às lixeiras que cada morador tem em sua própria calçada.

No caso de moradores utilizarem as estações para o lixo orgânico, os próprios coletores farão um levantamento dos bairros para apontar em quais locais há a necessidade de um mutirão extra para melhorar a conscientização socioambiental dos habitantes, novamente, é preciso persistir para que ideia enraíze em todas as residências.

\section{CONCLUSÃO}

A pesquisa teve como objetivo apontar e amenizar os motivos pelos quais os habitantes de Presidente Epitácio não assumem inteiramente suas responsabilidades socioambientais perante a coleta seletiva do município.

Assim, embasado na Secretaria do Meio Ambiente de Presidente Epitácio, evidenciamos que a cidade necessita de estações para uma coleta seletiva mais eficaz, que proporcione espaços urbanos que incentivem a colaboração de todos e melhore o volume coletado pela Cooperarpe.

Desta forma, as futuras estações de coleta seletiva irão cumprir com os resultados do presente artigo e possivelmente inspirar outras cidades da região do Oeste Paulista. Isso salienta 
que o estudo é relevante e facilmente adaptável para qualquer cidade, e assim, dá abertura para que novas regiões adquiram essa ideia e que as estações se expandam para todo o Brasil.

\section{REFERÊNCIAS}

OLIVEIRA, Ademir. Situação Atual de Presidente Epitácio: Coleta Seletiva. Presidente Epitácio, Secretaria do Meio Ambiente, 19 jun. 2016, 07:58:00. Entrevista direcionada para Yucca Arquitetura e Economia Sustentável.

Portal Joia Ribeirinha. Prefeitura de Presidente Epitácio: Cooperativa de Coletores de Recicláveis. 2015. Disponível em: <http://joiaribeirinha.com.br/site/?p=8813>. Acessado em 20 jun. 2016, 18:10:00.

WARREN, Cortney S. Lies We Tell Ourselves: The Psychology of Self-Deception. 1. Ed Insight Publishing, 2014.

ARBINGER, Instituto. Leadership and Self-Deception. 1. Ed Editora Penguin UK, 2000.

TRIANDIS, Harry C. Self-Deception: An Introduction. Disponível em: <http://www.scielo.org.mx/scielo.php?script=sci_arttext\&pid=S2007-

48322013000200002\&lang=pt>. Acessado em 05 set. 2016, 15:25:00.

FINGARETTE, Herbert. Self-Deception : With a New Chapter. 1. Ed University of California, 2000.

GOFFI, Gabriel. Como Atingir a Alta Performance: ExpoTrader. 2015. Disponível em: <https://www.youtube.com/watch?v=js|OB4vl8tY>. Acessado em 20 jun. 2016, 09:34:00.

Portal Joia Ribeirinha. Gestão do Lixo: Aterros Sanitários. 2016. Disponível em: <http://joiaribeirinha.com.br/site/?p=29158>. Acessado em 24 jun. 2016, 13:48:00. 